\title{
U.S. Geological Survey (USGS) Western Region: Kasatochi Volcano Coastal and Ocean Science
}

A laska is noteworthy as a region of frequent seismic and volcanic activity. The region contains 52 historically active volcanoes, 14 of which have had at least one major eruptive event since 1990. Despite the high frequency of volcanic activity in Alaska, comprehensive studies of how ecosystems respond to volcanic eruptions are non-existent. On August 7, 2008, Kasatochi Volcano, in the central Aleutian Islands, erupted catastrophically, covering the island with ash and hot pyroclastic flow material. Kasatochi Island was an annual monitoring site of the U.S. Fish and Wildlife Service, Alaska Maritime National Wildlife Refuge (AMNWR); therefore, features of the terrestrial and nearshore ecosystems of the island were well known. In 2009, the U.S. Geological Survey (USGS), AMNWR, and University of Alaska Fairbanks began long-term studies to better understand the effects of the eruption and the role of volcanism in structuring ecosystems in the Aleutian Islands, a volcano-dominated region with high natural resource values.

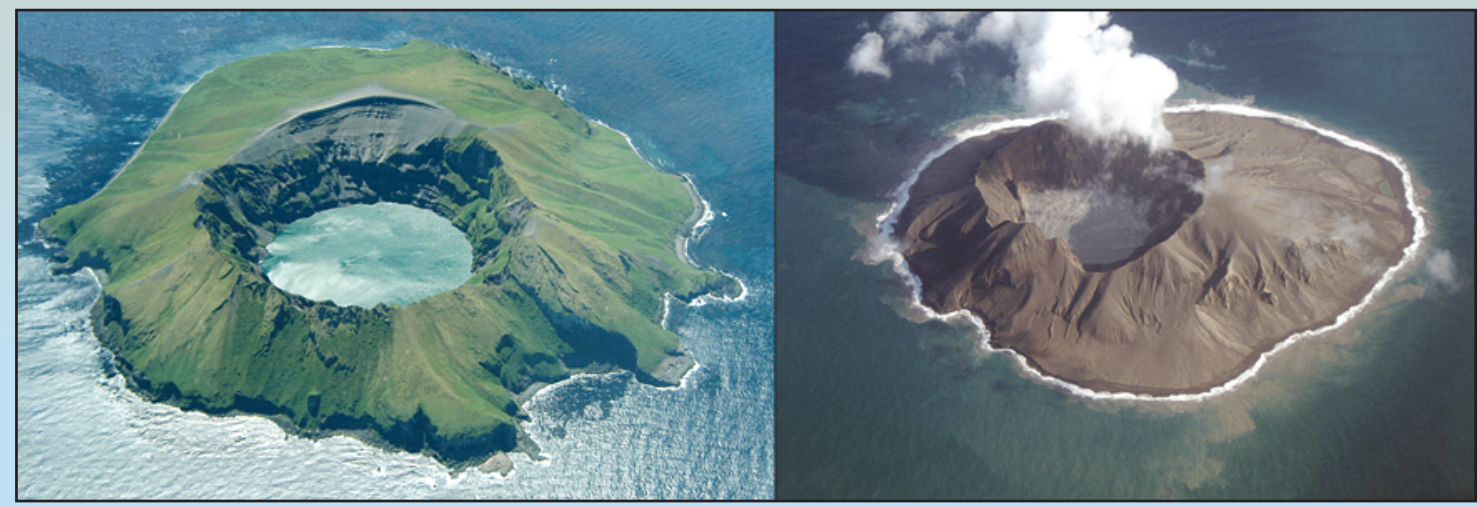

Kasatochi Volcano in July 2008 (left) and in October 2008 (right). The volcano erupted August 7, 2008. Photographs taken by Jerry Morris, Security Aviation.

\section{Pre-eruptive Kasatochi}

Kasatochi is a small stratovolcano in the central Aleutian Islands. Prior to the eruption, the volcano was about $3 \mathrm{~km}$ in diameter, $300 \mathrm{~m}$ high, with a steep-walled caldera with a small lake in the center. Because of the nature of its water-filled caldera and steep, verdant slopes, Kasatochi was one of the most picturesque of the Aleutian Islands. Before the 2008 eruption, the island was steep and rugged with dense, low-growing vegetation dominated by many species of grasses and forbs making it similar to other Aleutian Islands. Kasatochi Island was set apart by the diversity and abundance of seabirds that nested there each summer. Most notably, Kasatochi supported a colony of about 250,000 least and crested auklets, one of only seven such colonies in the Aleutian chain. The large numbers of seabirds attracted a variety of avian predators such as bald eagles and peregrine falcons. Kasatochi was also notable for supporting a rookery of the endangered Steller sea lion.

As the photographs of Kasatochi taken in 2008 suggest, life on the island appears to have been destroyed by the August 7 eruption. During summer 2009, we began a study to understand how Kasatochi had changed over the winter and to determine the initial fate of the terrestrial and marine plants and animals on the island. 


\section{Research Objectives}

Our long-term goal is to examine how terrestrial, nearshore, and marine ecosystems at and around Kasatochi Island respond to the cataclysmic eruption of August 7,2008. This is a unique opportunity to examine how volcanism and geomorphologic processes influence ecosystem succession on a remote maritime island through the integration of various scientific disciplines. Kasatochi provides a real-world laboratory where island biogeographic theory and the factors that influence dispersal and re-settlement of plant, invertebrate, and vertebrate species can be examined.

\section{Post-eruption Research in $\mathbf{2 0 0 9}$}

During summer 2009, teams of geologists, botanists, ornithologists, and marine ecologists visited Kasatochi and nearby islands four times to document the effects of the eruption and establish baseline conditions from which long-term comparisons will be made. The teams were supported in the field by the U.S. Fish and Wildlife Service's vessel, the M/V Tiglax. The teams set up equipment such as seismometers, time-lapse cameras, and bird song meters. They also established permanent transects and plots for sampling and for making detailed measurements.

\section{Preliminary Findings From Summer 2009 Investigations}

\section{Geology and Geomorphology}

- The 2008 volcanic deposits contained a large proportion of lithic blocks (pieces of the preexisting volcano) indicating that the upper part of the cone was blown away during the eruption.

- Larger-than-expected variation was noted in thicknesses of the pyroclastic deposits and the extent to which the pre-eruption surfaces were affected. In some areas, the deposits were tens of meters thick and the existing ground cover was stripped off. In other areas, the deposits were thin, already eroded, and showing pre-eruption surfaces.

- The rapidity of the modification and erosion of the 2008 deposits is remarkable. Large gully systems have developed and the upper 1-2 meters of deposits in steep areas have sloughed off and generated debris flows resulting in considerable sediment deposition in nearshore marine waters.

- Kasatochi continued to degas (sulfur gasses and perhaps carbon dioxide) more than 1 year after the eruption, likely from diffuse sources.

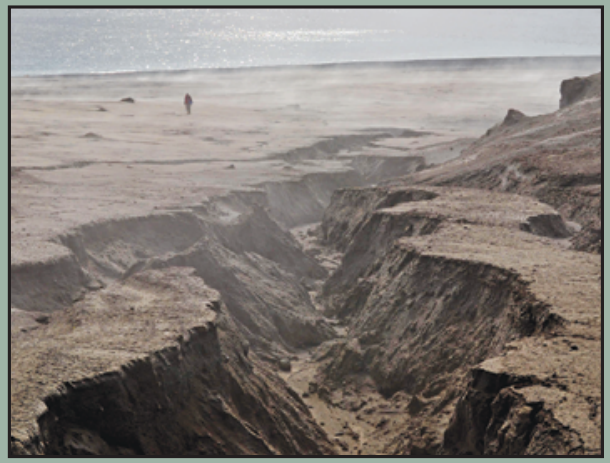

Example of extreme rapid erosion of pyroclastic material from Kasatochi. Photograph by Chris Waythomas, U.S. Geological Survey.

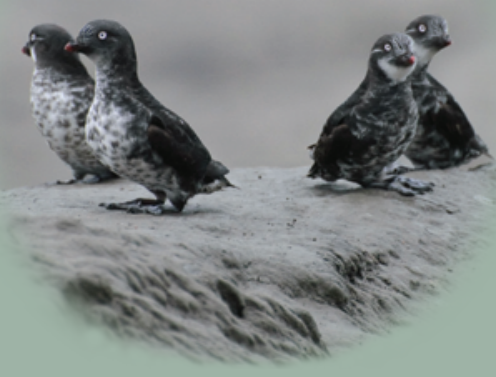

Marine Ecology

\section{Terrestrial Ecology}

- Some pre-existing vegetation seems to have survived the eruption, particularly in areas that were protected from the hot pyroclastic flows or where the flows eroded off quickly.

- Scattered individuals of several plant species and one small remnant plant community were observed. Most of the plants likely originated from rhizomes, rootstock, or seed banks that survived the eruption.

- A few terrestrial arthropods may have survived as well. Wingless carrion beetles as well as a centipede and a spider were found. Several fly species (kelp flies and a blowfly) also were found and these species already were exploiting bird carcasses and kelp that had washed up on the island.

- Many birds returned to the island although none nested successfully. The auklet colony was buried under volcanic debris and ash, but hundreds of thousands of auklets still attended the former colony site. The auklets were unable to locate suitable nesting crevices and laid eggs on the ground or in the water. Nearly all birds were gone by August.

- Steller sea lions were the only wildlife species to breed successfully.

- The nearshore, subtidal zone was largely devoid of life. Most of the kelp forests around the island had been covered with volcanic debris and most of the seafloor was comprised of unstable sediments. Little recovery was observed. Continued deposition of sediments into the nearshore due to erosion of deposits on Kasatochi likely will have long-term effects on the nearshore marine ecosystem.

\section{Summary}

Kasatochi has changed rapidly since the August 2008 eruption. Our multidisciplinary team of researchers will continue to document these changes in 2010 and beyond.

Financial support from the North Pacific Research Board, the USGS Office of the Alaska Regional Executive, the U.S. Fish and Wildlife Service, the USGS Alaska Science Center, and the Alaska Volcano Observatory is gratefully acknowledged.

\section{For more information:}

Director, Alaska Science Center

U.S. Geological Survey

4210 University Drive, Anchorage, AK 99508

907-786-7000

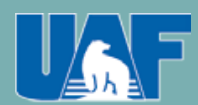

FAIRBANKS
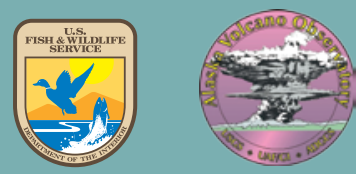